\title{
Do Namoro ao Casamento: Significados, Expectativas, Conflito e Amor ${ }^{1}$
}

\author{
Sofia Raquel Alves Fonseca \\ Cidália Maria Neves Duarte \\ Universidade do Porto
}

\begin{abstract}
RESUMO - O presente estudo, de cariz exploratório, analisa i) os significados de casamento e amor, ii) as expectativas para o casamento, o cônjuge e o próprio, e iii) a emergência e resolução do conflito, em duas fases: namoro e casamento. Com base numa entrevista semiestruturada, entrevistaram-se cinco casais heterossexuais (cada cônjuge separadamente) casados há pelo menos dois anos, sendo que o namoro foi explorado retrospetivamente. Para o tratamento dos dados, recorreu-se à análise de conteúdo. Concluiu-se que as díades, no namoro, não exploram intencionalmente os significados e expectativas para o casamento; que este assume diferentes significados; que as expectativas, quando casados, veem-se correspondidas ou superadas; e, no casamento, surgem novas fontes de conflito bem como pequenas mudanças nas estratégias de resolução.
\end{abstract}

Palavras-chave: namoro, casamento, significado de casamento, expectativas, conflito

\section{From Dating to Marriage: Meanings, Expectations, Conflict and Love}

\begin{abstract}
The present, exploratory, study analyses i) the meanings of marriage and love, ii) the expectations for marriage, for the partner and for oneself, and iii) the rising and resolution of conflict, in two stages: dating and marriage. Using a semistructured interview, five heterosexual couples, married for at least two years, were interviewed (each member separately), and dating was explored in retrospective. Content analysis was used as the data analysis strategy. It was concluded that couples, while dating, do not explore the meanings and expectations for marriage intentionally; that marriage assumes different meanings; that expectations are matched or surpassed; and that there are new sources of conflict in marriage as well as small changes in coping strategies.
\end{abstract}

Keywords: dating, marriage, marital meanings, expectations, conflict

$\mathrm{O}$ amor e as relações de intimidade são parte integrante e central na vida dos indivíduos (Wright, Simmons, \& Campbell, 2007), dado que estes têm uma necessidade básica para ser aceites e cuidados e retribuir essa aceitação e cuidado - em suma, de amar e ser amado (Fletcher, 2002). Embora inquestionável a importância desse processo de união nas biografias individuais (Aboim, 2006), o casamento, enquanto forma mais comum de oficializar as relações de intimidade, nem sempre se imbuiu dos mesmos significados, oscilando em função das constantes e naturais transformações sociais.

Numa conjuntura de conjugalidades em mudança, assistindo-se em Portugal a um progressivo crescendo das uniões de facto e da coabitação como experiência prévia ao casamento (Leite, 2003), a uma escalada do número de separações e divórcios e a um decréscimo do número de casamentos celebrados (INE, 2010), é pertinente refletir sobre o casamento e desvelar os seus significados. Existem, inclusive, evidências de que o modo como este é compreendido está relacionado com o funcionamento e comportamento conjugal (Hall, 2006).

Com uma longa história e com estatuto de uma das noções socioculturais com maior impacto na vivência

1 Apoio: Fundação para a Ciência e a Tecnologia

2 Endereço para correspondência: Faculdade de Psicologia e de Ciências da Educação da Universidade do Porto, Centro de Psicologia da Universidade do Porto, Rua Alfredo Alen, s/n, Porto, Portugal. CEP 4200-135.E-mail: sfonseca@fpce.up.pt humana (Rosa, 2009), no último século o casamento passa de unidade essencial de sobrevivência económica a símbolo da liberdade individual de que gozam as sociedades ocidentais (Leite, 2003), passando a ter na sua génese o ideal romântico do amor (Acevedo \& Aron, 2009; Carminatti, 2009; Duarte, 2011; Ribeiro, 2002). Não obstante ser encarado como fator de estabilidade pessoal, hoje em dia é recorrentemente questionado. Para uns, assiste-se a uma alteração dos valores e das representações em torno do casamento e das suas finalidades, denotando uma visão mais laica e desvalorizadora do aspeto sacramental e institucional (Leite, 2003). Para outros, mais do que uma recusa do casamento, trata-se de novas e plurais formas de encadeamento entre namoro, vida em comum e casamento, visto que a maior parte das experiências de conjugalidade informal são transitórias (Aboim, 2005). De um modo geral, a investigação reflete a continuidade do desejo de celebrar o casamento e apresenta-o positivamente percecionado pelos jovens, nomeadamente enquanto compromisso vitalício (Martin, Specter, Martin, $\&$ Martin, 2003).

Devido ao retrato das relações conjugais nos media, o casamento é fortemente expectado, tal como ilustra o Modelo Epigenético de Compreensão das Expectativas Conjugais proposto por Bhatti (1993): as expectativas para cada um enquanto parceiro, as expectativas para o casamento, as expectativas de e para ambas as famílias de origem, as expectativas para o casamento enquanto instituição e a 
imagem ou conceito de parceiro ideal. De acordo com Baucom et al. (1996), as expectativas são "previsões sobre o futuro da relação em áreas específicas do funcionamento conjugal" (p. 210). Para a sua construção contribuem variáveis como as normas sociais e o contexto sociocultural em que se vive (Juvva \& Bhatti, 2006), a estrutura e as experiências familiares desde a infância (Flouri \& Buchanan, 2001; Morris \& Carter, 1999), as experiências com os pares e as relações românticas que se vão estabelecendo (Hall, 2006; Shulman, Rosenheim, \& Knafo, 1999) e ainda os meios de comunicação social (Holmes \& Johnson, 2009).

Não obstante a literatura ser consensual quanto à influência das expectativas dos cônjuges para os seus relacionamentos na avaliação que fazem desses mesmos relacionamentos, não é unânime a direção desse efeito. Uma das linhas de investigação defende que expectativas positivas conduzem a resultados positivos como o funcionamento saudável da relação (McNulty \& Karney, 2004). Outra, por sua vez, considera que expectativas positivas levam a desapontamentos e, consequentemente, a disfuncionalidade conjugal (Bonds-Raacke, Bearden, Carriere, Anderson, \& Nicks, 2001; Wright et al., 2007). A resposta parece prenderse com os diferentes objetivos que as expectativas podem cumprir - objetivos estruturais que motivam e encorajam a sua confirmação, revelando-se benéficas, ou contrafactos com os quais os cônjuges comparam a sua relação atual, resultando numa avaliação mais negativa por parte destes (McNulty \& Karney, 2004).

Com efeito, pode indagar-se sobre a possibilidade do aumento do número de divórcios significar o insucesso dos cônjuges em fazer corresponder o casamento às expectativas que tinham (Ribeiro, 2002; Torppa, 2009). O facto de a maioria ocorrer nos primeiros anos de casamento poderá corroborar essa fantasia em torno do matrimónio já que a fase inicial é a de maior idealização e, concomitantemente, quando ocorre o confronto com a realidade concreta e palpável da vivência a dois que nem sempre valida e consolida essas idealizações. Pensa-se que a vivência do namoro tem alguma influência nestas discrepâncias ao nível do que os cônjuges esperam (Bonds-Raacke et al., 2001), de modo que é pertinente e necessária a investigação sobre os primeiros tempos de relacionamento. $\mathrm{O}$ presente trabalho pretende precisamente reduzir a ausência de investigação que se debruce sobre ambas as fases relacionais, explorando o "agora" sem esquecer o "antes".

Mas, se as relações de intimidade são expectadas enquanto sinónimo de bem-estar, não escapam também a emoções e pensamentos mais escuros (Fletcher, 2002). O conflito é consubstancial e indeclinável à natureza humana, atribuindo-se-lhe ainda outra característica antitética à sua conceção tradicional - a necessidade (Jares, 2002), visto que é promotor de desenvolvimento, diferenciação e autonomia e, consequentemente, de intimidade (Costa, 2005). Frequentemente associados ao seu despoletar estão fenómenos como as diferenças individuais, a falta de companheirismo e proximidade emocional, as expectativas não correspondidas (Esere, 2003), a percepção de desigualdade laboral, as experiências extraconjugais, o consumo de álcool e drogas (Fincham, 2003), as famílias de origem, as finanças, a comunicação, os filhos e o grupo de pares (Baucom \& Epstein, 1991).

O conflito não é necessariamente destrutivo, sendo a gestão e a habilidade do casal para lidar (des)adequadamente com ele que o determina. As respostas ao conflito apenas são construtivas quando incluem afetos positivos, humor, resolução de problemas, acordo, aceitação, empatia e escuta ativa (Gottman, 1991). Ao contrário, sequências de manipulação, ameaça e coerção, retaliação, inflexibilidade, rigidez, evitamento, dominância e subordinação aliadas à comunicação verbal e não-verbal negativas são estratégias em que o conflito é encarado destrutivamente (Greeff \& Bruyne, 2000), o que se verifica nos casais mais insatisfeitos.

Entre os significados que assumem, as expectativas de que se revestem e os conflitos que inexoravelmente nelas se atravessam, as relações de intimidade têm como substrato a afetividade, nomeadamente o amor. Há séculos que este não perde a titularidade de sentimento mais declamado, procurado e desejado, e vem sendo evocado como razão de viver e sofrer, carregando a responsabilidade tanto das felicidades humanas como das suas mazelas (Oltramari, 2009). Existe uma panóplia de abordagens e perspetivas sobre o amor, as quais permitem perceber que paixão, intimidade e compromisso são considerados os seus principais componentes (e.g., Sternberg, 1986), apesar de não serem sentimentos e não haver unanimidade no que se refere à relação entre eles e à importância de cada um. Mais do que os diferentes "amores" que derivam das suas combinações, devem sobressair as suas interações, sublinhando-se que à medida que a relação se atravessa no tempo, nenhum componente pode permanecer igual (Narciso, 1994/1995). É em comunhão com essa perspectiva dinâmica que os resultados mais recentes avançam ser possível a manutenção da paixão em relações de longa duração, em detrimento do que tem sido amplamente acreditado (Acevedo \& Aron, 2009), devendo atender-se a confusões terminológicas que, muitas vezes, estão na base do pressuposto de que relações de muitos anos matam o amor romântico.

Portanto, embora exista investigação tanto acerca do namoro como do casamento, escassos estudos cruzam ambas as fases e se pautam por uma perspetiva de continuidade. A par, também é reconhecida a necessidade de mais pesquisa para aceder a uma visão mais detalhada, por exemplo, dos significados do casamento e das expectativas que sobre e para ele desenvolvem (Kefalas, Furstenberg, \& Napolitano, 2005; Morris \& Carter, 1999).

\section{Método}

Dada a impossibilidade de entender o casal isolado do tempo (Narciso, 1994/1995), o presente estudo, assente numa intenção heurística e exploratória (Bardin, 2009), explorou, na fase de namoro e na de casamento, 1) os significados da instituição casamento, 2) as expectativas para o casamento, o parceiro e o próprio na relação e a sua correspondência, e 3) o conflito (emergência, fontes e estratégias de resolução). Tendo em conta a inexorável importância do afeto na conjugalidade (Gottman \& Notarius, 2002), também 
se procurou aceder 4) aos significados do amor e à sua importância na conjugalidade.

$\mathrm{Na}$ certeza de que são os narradores os verdadeiros especialistas das suas próprias "histórias", optou-se pela metodologia qualitativa para apreender os significados inerentes à vivência dos sujeitos.

\section{Participantes}

Foram entrevistados cinco casais heterossexuais (cada cônjuge separadamente), cinco sujeitos do sexo feminino e cinco do masculino com idades compreendidas entre os 26 e os 37 anos $(M=30,7)$, que respeitavam as seguintes características: dois anos, no mínimo, de casamento, ausência de coabitação prévia ao casamento, primeira experiência matrimonial e ausência de filhos. $\mathrm{O}$ tempo de namoro variava entre os dois anos e meio e os nove anos, e o tempo máximo de casamento eram cinco anos. Relativamente às habilitações literárias, todos os participantes têm formação superior, à exceção de um que tem o nível secundário, e apresentam as seguintes profissões: gestora e engenheiro; psicóloga e engenheiro; enfermeira e serralheiro; média e economista; e enfermeira e técnico bancário. Seis dos participantes eram Católicos, dois Adventistas do Sétimo Dia e dois não tinham religião.

\section{Instrumento}

O guião da entrevista semiestruturada foi construído de raiz a partir da literatura, foi submetido ao olhar de um especialista nas questões da conjugalidade e da intervenção com casais e ensaiado numa entrevista experimental. $\mathrm{Na}$ exploração que era feita no decorrer das entrevistas, eram tidos em conta aspetos que a literatura considera importantes para a compreensão dos fenómenos em estudo, nomeadamente a influência das experiências familiares e experiências românticas prévias na construção dos significados e das expectativas acerca do casamento.

O guião contempla um primeiro momento relativo aos dados demográficos, é constituído por 29 questões e pode ser dividido em três partes. A primeira refere-se ao período de namoro, incluindo os significados do casamento (e.g., No tempo em que namorava, o que significava o casamento para si?), as expectativas para o mesmo (e.g., Enquanto namoravam, quais as suas principais expectativas para o casamento com o/a seu/sua atual marido/mulher?) e o conflito (e.g., Relativamente à fase de namoro, quais eram os temas dos vossos conflitos?). A segunda refere-se ao casamento, nomeadamente a eventuais alterações nos significados a ele associados (e.g., Sente que o significado que atribuía ao casamento enquanto namorava mudou depois de ter casado? O que significa agora?), à correspondência ou não das expectativas (e.g., Em que medida o/a seu/sua marido/ mulher corresponde ou não ao que imaginou?) e ao conflito (e.g. Habitualmente, como é que gerem e resolvem os conflitos?). E, por fim, a terceira diz respeito ao amor e à sua importância na conjugalidade (e.g., Como define o amor e a importância que ele tem nestas questões?), possibilitando ainda aos participantes eventuais considerações.

\section{Procedimento}

A seleção dos participantes foi realizada "por conveniência". Relativamente à recolha de dados, as considerações de natureza ética foram tidas em conta, na medida em que se explicaram os objetivos do estudo e se garantiu a confidencialidade, assinando ainda os participantes uma declaração de consentimento informado permitindo a gravação da entrevista em suporte áudio (para posterior transcrição integral). As entrevistas foram realizadas separadamente a cada elemento do casal para garantir um maior à vontade e sinceridade no discurso e encontrar pontos de convergência e divergência nas suas narrativas. $\mathrm{O}$ tratamento das narrativas foi feito através da análise de conteúdo (Bardin, 2009). Na "pré-análise", a partir das transcrições integrais dos discursos, procurouse uma organização inicial e não estruturada para os dados, partindo de impressões subjetivas e adquirindo, progressivamente, uma leitura mais precisa dos mesmos. Seguiu-se a "exploração do material", na qual se transformou o texto bruto em categorias, subcategorias e componentes, por meio da codificação e de uma análise de conteúdo temática que teve em conta os temas do guião da entrevista. Por fim, procedeu-se ao "tratamento dos resultados", sua inferência e interpretação.

\section{Apresentação e Discussão dos Resultados}

\section{Namoro}

Não obstante a parca reflexão acerca do significado de casamento evidenciada ("Sei lá, eu acho que não é uma coisa que a pessoa pense quando namora" - $\mathrm{c} 2 \mathrm{f}$ ), este, na fase de namoro, era "uma coisa que mais cedo ou mais tarde iria acontecer" (c2_m), que "era lógico" (c1_f) e "normal" (c3 m), indo ao encontro da perspectiva do ciclo de vida da família, onde a transição para o casamento sinaliza significativamente o início de uma etapa (Lindahl, Malik, \& Bradbury, 1997; Myers, 1998). A justificar essa visão de casamento enquanto algo sequencialmente lógico estão o processo educacional e de socialização ("Era muito incutida a ideia do casamento. Nós brincávamos a vestir as bonequinhas de noivas e fazíamos casamentos uns para os outros" - c5_f), e as experiências familiares ("Cresci, os meus familiares eram praticamente todos casados e isso, foi uma consequência" - c3_m), o que era de esperar visto que o processo de formação de atitudes e até mesmo de expectativas face ao casamento tem o seu início na infância (Morris \& Carter, 1999). Percebe-se como, apesar da crescente proliferação de novas configurações familiares, ainda subjaz à nossa cultura o ideal do casamento, da sua estabilidade $\mathrm{e}$ importância (Amaro, 2004).

Para além de um marco, para a maioria o casamento configurava um objetivo desejável que iria ter lugar nalgum 
ponto das suas vidas, como estudos demonstram acontecer com um grande número de jovens (Kefalas et al., 2005). Mas se, por um lado, o casamento "sempre fez parte" (c5_f), ideia muito alicerçada no processo educacional e de socialização e nas experiências familiares, por outro era encarado como um acontecimento a longo prazo, "uma coisa que estava para um dia" (c2_m) e que "nem se quer fazia parte da equação inicial" (c4_m).

Enquanto namoravam, casamento também significava "uma aposta naquela pessoa e na relação" (c1_f), lembrando Fletcher e Simpson (2000), para quem, particularmente no panorama contemporâneo das relações tingidas por elevadas taxas de divórcio, casar exige um voto de fé e um nível de confiança difíceis de justificar de um ponto de vista puramente racional. A par, significava o reconhecimento desse compromisso e afirmação perante a sociedade (" $O$ reconhecimento perante... os amigos, a família e a sociedade em geral que nós, de facto, pertencíamos um ao outro" c4 m).

Se para alguns dos participantes, aqueles para quem a dimensão religiosa assumia maior preponderância, o casamento estava relacionado com o valor e importância do "sacramento" (c1_m; c4_f), ele era claramente menos valorizado por outros ("Nunca atribuí assim muita importância ao casamento" - c5_m), afigurando-se um "contrato" (c2_f) e "um formalismo" (c5 m). No fundo, as significações emergentes oscilavam entre dois pólos, conceptualizados por Hall (2006) numa análise da literatura acerca do tema: o casamento cuja natureza é elevada e distinta de outros estatutos e tipos de relações de intimidade e o casamento enquanto apenas uma de entre as várias formas possíveis de uma relação íntima ser equacionada. No extremo, para um dos participantes, enquanto namorava, casamento era sinónimo de "má vida", dada a existência de anteriores experiências relacionais negativas e o contacto com casamentos pautados por conflito. Esse exemplo evidencia como também nas raízes da significação de casamento estão os relacionamentos prévios e as experiências familiares, sendo importante atender e aceder a eles na intervenção psicológica.

Quando questionados acerca dos significados de casamento na fase de namoro mas relativamente ao cônjuge, o desconhecimento e as expressões de dúvida ilustraram como a discussão dos significados de casamento de cada um dos parceiros não era intencionalizada enquanto namoravam ("nunca falamos sobre isso" - c4_f). Comparativamente, a abordagem das expectativas revela ser uma dimensão mais complexa, já que é determinada pelo tempo de relação, sendo diminuta no início pela existência de projetos precedentes e mais imediatos (e.g., académicos), o que denota a importância de situar as relações na linha do tempo. Quando abordadas, eram-no informal e espontaneamente ("ia surgindo" - c2_m), sendo que mais do que as expectativas para o casamento discutiam a "relação em termos de continuidade, fosse marcada pelo casamento ou pelo viver juntos" (c2 f).

Repare-se que, embora a partilha de expectativas fosse acontecendo, esta não era suficiente ("algumas expectativas que ela criava e que eu não me apercebia que ela tinha criado essas expectativas, quando saiam um bocadinho ao lado, ela ficava muitíssimo desiludida e abatida" - c1_m), alertando para a necessidade de explorar mais profundamente as expectativas do próprio e do parceiro, como meio de prevenção da conflitualidade.

É possível que, em parte, essa ausência de uma reflexão intencionalizada tanto dos significados como das expectativas se deva à ausência de tradição de pensar as relações no seio familiar, predominando uma comunicação centrada nos aspetos triviais e funcionais do quotidiano (Torppa, 2009). É, portanto, necessário sensibilizar para a importância de discutir dimensões cognitivas importantes nas relações, visto que efetivamente a mente da relação influencia significativamente o comportamento e o modo como estamos nela.

Ainda assim, o casamento era expectado enquanto encontro de um "companheiro para toda a vida" (c3_f), emergindo o caráter vitalício que, à partida, esse compromisso configura concebendo-se o seu término apenas sob circunstâncias extremas, tal como parece ainda acontecer, apesar de tudo, com grande parte dos jovens adultos (Markman, Rhoades, Stanley, Ragan, \& Whitton, 2010; Torppa, 2009). Partilhar uma filosofia de vida ("era partilharmos os mesmos valores" - c1_f) e dar resposta a uma necessidade de segurança e apoio, "emocional e... instrumental" (c2_f) eram expectativas também consonantes com a literatura (Hall, 2006; Myers, 1998). A somar, esperavam construir "um lar" (c2_m), aumentar a intimidade e o tempo conjunto ("aumentar a qualidade e o tempo de partilha" - $\mathrm{c} 4$ f) e construir uma família onde os "filhos" surgiriam, ansiando uma nova dinâmica relacional na qual estar com o outro "passaria a ser a coisa natural do dia a dia" (c1_m). No fundo, sustendo a felicidade conjunta como expectativa basilar ("acordarmos os dois bem-dispostos e estarmos os dois felizes ao lado um do outro" - c2 m), o casamento assumiase como a fórmula para "acima $\bar{d} e$ tudo, ser feliz" (c5_f). É precisamente enquanto projeto de realização da felicidade e de necessidades como o amor, a intimidade e o compromisso que é patenteado na literatura (Morris \& Carter, 1999). Não obstante, por influência das concepções sociais ("Pelo que me diziam" - c4_m), já esperavam a diminuição da "margem de manobra" individual e a necessidade de "cedências de parte a parte" (c4_m).

Uma leitura global dos significados e expectativas na fase de namoro demonstrou que, pese embora maioritariamente representado enquanto opção pela felicidade, não ostentavam uma visão demasiado idealizada expectando a perfeição "[O casamento] não é um floreado, não é uma telenovela de se pensar que a vida vai ser sempre cor-de-rosa... Nunca pensei que [ela] fosse uma pessoa perfeita no sentido em que nunca iria fazer nada que me irritasse um bocadinho... A vida não vai ser feita só de momentos bons e se as pessoas não tiverem... preparadas para no momento das dificuldades manterem a noção do que é mais importante, vão ter uma vida muito complicada. Porque as dificuldades vão aparecer e elas vão procurar uma forma de fugir a elas à procura de um facilitismo e de uma alegria constante que não existe." (c1_m). Essa consciência revelou-se muito necessária para o bem-estar da relação num estudo qualitativo que explora as expectativas que várias mulheres, depois de casadas, consideram ter sido negativas e destrutivas para a qualidade e estabilidade conjugal (Faubert, 2008). 
Relativamente aos conflitos na fase de namoro, consideraram que não eram frequentes alegando ser a "fase do tudo é bonito e tudo se aceita" (c1_f). Na sua fonte, estavam regularmente características pessoais, nomeadamente diferenças na valorização ou na atenção dirigida a determinados acontecimentos ("os nossos conflitos tinham a ver com eu não ter dado uma importância a determinada coisa... semelhante ao que ela deu." - c1_m), na expressão emocional ("ela, por vezes achar que eu era muito pouco expressivo quer nas alegrias quer nas tristezas" - $\mathrm{c} 1 \mathrm{~m}$ ) e na postura e ritmos de vida ("o facto de eu ser uma pessoa muito organizada e um bocadinho obsessiva e o [ele] é uma pessoa um bocadinho mais desligada" - c2_f). Esere (2003) sugere que, podendo ser inúmeras as diferenças entre os parceiros numa relação, estas, ainda que não incitem necessariamente ao conflito, aumentam a sua possibilidade de ocorrência. Às características pessoais, somavam-se as diferentes necessidades e tempos na relação, "as relações anteriores que as pessoas têm" (c2_f), as famílias de origem, e o grupo de pares ("eu 'tava habituado a conviver com umas pessoas, às vezes forçava um bocado para estar com elas, [ela] não 'tava tão agradada com isso e o contrário também acontecia."-c4_m).

A respeito da emergência do conflito propriamente dita, constataram-se diferenças de género notórias condizentes com a literatura, verificando-se por parte delas uma menor probabilidade de o evitar e uma maior tendência para o incitar, ao passo que eles mais frequentemente o evitam e se retiram (Faulkner, Davey, \& Davey, 2005; Fincham, Beach, \& Davila, 2004; Narciso, 1994/95) - "Ele dá qualquer coisa para não ter uma discussão." (c3_f); "Eu sou uma pessoa que gosto muito pouco de discutir e, portanto, quem levantava as questões normalmente nunca era eu." (c1_m). Uma vez que as mulheres mais frequentemente se definem em termos dos seus relacionamentos (Myers, 1998), pode indagar-se sobre a possibilidade de por isso ser maior a sua preocupação com a relação, sendo consequentemente mais exigentes e mais difíceis de satisfazer.

Ao nível das estratégias de resolução, recorrentemente usufruíam do afastamento natural inerente à condição de namoro ao permitir uma relativização das situações ("Cada um acabava por ir para sua casa e no dia a seguir...já parecia que foi ridículo a discussão" - c1_f), bem como do tempo a ele associado que, por sua vez, possibilita a resignificação ("se deixarmos passar algum tempo pomos as coisas noutros termos, mudar ligeiramente uma ou outra nuance até conseguirmos entrar em acordo e haver um consenso entre os dois" - c4_m).

A comunicação era também um mecanismo de resolução por excelência, reconhecendo que uma comunicação aberta e eficaz é essencial para o crescimento e desenvolvimento pessoal e ainda para o entendimento e sucesso conjugal (Morris \& Carter, 1999; Myers, 1998). Do ponto de vista da qualidade da comunicação, ambos assumiam diferentes posturas, sendo elas mais interventivas ao passo que eles recorriam mais ao silêncio ("Discutíamos. Eu discutia! E ele dizia 'A bicicleta é tua!'... e eu ainda ficava pior, porque eu gosto de luta e ele não gosta nada de luta" - c3_f). Este configurava também uma estratégia que contribuía eficazmente para a resolução ("o silêncio dele ajuda de alguma maneira" - c4_f). Esse padrão de interação aquando da gestão da conflitualidade já dava indícios de proximidade com o padrão "Exigência-Retirada" que, no período de casamento, se viria a afirmar. No processo de resolução, destacam ainda a cedência, o sentido de humor e, para um dos casais, a oração, dado que permitia uma maior consciencialização do que estava realmente em causa ("Eu fazia a oração e chorava... e depois ligava-lhe e pedia desculpa" - c3 f).

\section{Casamento}

Depois de consumado o casamento, parte dos participantes apresenta uma manutenção dos seus significados. Contudo, alguns aperceberam-se que este é uma descontinuidade da experiência de namoro ("antes do casamento uma pessoa vê um continuar da relação de namoro... Não é a continuação do namoro" - c1_f), quer pelo "peso" que imprime enquanto afirmação vitalícia, quer pela coabitação implicada ("casamento, só por si, tem o peso de a pessoa sentir que teve... uma afirmação para o resto da vida... Não é a continuação do namoro, a pessoa depois, para o bem e para o mal, tem que saber aguentar" - c1_f). Aqueles que, no namoro, não o percepcionavam como tão difícil, apresentam agora uma percepção de casamento menos idealizada e mais consciente da dificuldade ("Pensei que podia ser mais fácil" - c4_m). Por sua vez, o participante cuja percepção era negativa resignifica-o, considerando que "não há melhor vida que a de casamento" (c3_f).

Relativamente à correspondência das expectativas para o casamento, de um modo geral todos consideraram que este correspondia, no momento presente, às expectativas traçadas. As expectativas desenvolvidas para o cônjuge também se encontravam correspondidas ou superadas. Ainda que o tempo de namoro e experiências como as férias e os fins de semana conjuntos que nele vão tendo lugar permitam conhecer bem o outro, o casamento, mais precisamente a experiência de coabitação ("Uma pessoa quando vive junta uma com a outra acaba por descobrir determinadas características" - c5_f), permite a descoberta de novas características (e.g., "vi uma outra faceta que eu não conhecia, de palhacinho a brincar com o pai" - c3 f; "Nunca imaginei que ele fosse desenrascar-se tanto" - $\mathrm{c} 4 \overline{\mathrm{f}}$;), e sobretudo uma maior consciencialização e valorização de algumas já conhecidas, uma redefinição nas atribuições e a percepção de uma maior intensidade. Todos os aspectos que se revelaram negativamente surpreendentes constituíramse motivo de conflito, alertando para a real necessidade e importância de um bom heteroconhecimento entre os cônjuges.

Sobre a correspondência das expectativas para si próprios enquanto cônjuges, a surpresa de quase todos evidenciou como a projeção no desempenho futuro do papel de cônjuge não era um exercício frequente em namoro. Não obstante, descobriram-se diferentes do que previamente expectavam nalgumas dimensões, diferenças que passam por uma maior flexibilização, uma maior necessidade de espaço individual, uma maior ou menor competência na gestão doméstica, e 
ainda uma maior facilidade na desvinculação às figuras parentais que o casamento proporciona.

No que respeita ao conflito, a sua emergência parece ter diminuído comparativamente com a fase precedente, ainda que no início, sobretudo num dos casais, se registe um aumento considerável ("O primeiro ano de casamento foi... muito mau. Nós tivemos imensos conflitos, até depois no final do ano tivemos conflitos graves." - $\mathrm{c} 1 \mathrm{~m})$. Foi notória a fase de ajuste que se impõe no início, sustentada na literatura que refere serem os primeiros anos, dois sobretudo, tempos de adaptação e aprendizagem, nomeadamente de como comunicar adequada e eficazmente com o outro e de como resolver construtivamente os conflitos. Numa perspetiva desenvolvimental, em que o casamento é concebido como atravessando diferentes estádios, cada um deles com os próprios desafios desenvolvimentais, a comunicação bem-sucedida e a resolução construtiva dos conflitos seriam as tarefas desenvolvimentais ao encargo dos recémcasados (Markman, Floyd, Stanley, \& Jamieson, 1984). Mas se o momento de construção de uma identidade conjugal é, muitas vezes, tumultuoso e com dificuldade acrescida, também é um período de fluxo onde os padrões de interação podem estar mais permeáveis à influência e à mudança (Behrens \& Sanders, 1994), o que pode constituir-se um bom aliado no processo do casal descobrir o seu "modus operandis".

Ao nível das fontes, mantêm-se as características pessoais e o grupo de pares, surgindo agora a vida sexual ("na vida sexual também não pensamos da mesma maneira... Depois de casados, para mim, a frequência devia ser para mim uma coisa mais... maior!" - c1_f) e sobretudo a vida profissional. $\mathrm{O}$ aumento da conflitualidade devido a esta última dimensão é suportado por um estudo com casais recém-casados que evidenciaram ser o equilíbrio entre a esfera profissional e a familiar a dimensão mais problemática (Risch, Riley, \& Lawler, 2003), e por outro que conclui que o conflito entre trabalho e família é exigente levando à exaustão emocional (Senécal, Vallerand, \& Guay, 2001). Ainda que o casamento traduza uma vontade de destacar e dar centralidade ao domínio familiar a dada altura do ciclo vital, a esfera profissional, sobretudo na contemporaneidade, não parece ser tão facilmente subordinada à primeira, mantendo-se ambas como muito relevantes para a realização pessoal e para o autoconceito, inclusive das mulheres (Senécal et al., 2001). Este crescendo da dimensão profissional enquanto fonte de conflitualidade pode justificar-se no facto de nesse momento do percurso de vida os indivíduos quererem consolidar a relação que será a base da sua família mas também a profissão que será a base da sua subsistência (Rosa, 2009), havendo uma coincidência temporal entre o desafio de identificação e consolidação com uma carreira e o desenvolvimento de uma crescente capacidade para a intimidade (Myers, 1998).

Em relação às estratégias de resolução dos conflitos, o "sentido de humor" mantem-se uma "ótima estratégia" (c4_m), havendo evidências que, de facto, a habilidade para usar afeto positivo durante os conflitos é essencial e prediz um futuro relacional saudável (Driver \& Gottman,
2004). De diferente, salientam a inexistência do afastamento espacial implícito na condição de namoro que ajudava à relativização e resolução, e acusam a acentuação do padrão "Exigência-Retirada" já saliente em namoro, na medida em que recorrentemente elas estão ativamente investidas, falando e exigindo, e eles mantêm-se defensivos e passivos para evitar os riscos da discussão. Essa constatação vai ao encontro da maioria dos estudos que revelam pertencer às mulheres o papel de exigir/atacar e o de retirar/evitar aos homens (Fincham, 2003; Fletcher, 2002) ("quando há conflitos eu sou mais de falar, falar, falar e [ele] é mais de estar calado. - c4_f; "normalmente resolve com: eu resmungo, pronto, ele ouve." - c5_f). Portanto, se o silêncio (deles) por vezes ajuda na resolução, noutras instala ou intensifica o conflito, sendo gerador de não satisfação nas mulheres (Narciso, 1994/95) "às vezes, quando a pessoa entra em conflito o silêncio dele ajuda de alguma maneira, se bem que de alguma maneira também me mexe ali com o sistema nervoso." (c4_f).

Segundo Verhofstadt, Buysse, Clercq e Goodwin (2005), para eles a retirada representa um mecanismo de evitamento da escalada, enquanto elas o leem como sinal de hostilidade. Adiantando hipóteses explicativas, os mesmos autores interrogam se os homens, do ponto de vista biológico, não estarão tão naturalmente equipados para lidar com situações de conflito, ou se o padrão encontra sustentação nas diferentes experiências de socialização a que homens e mulheres são sujeitos, nomeadamente no que concerne à gestão das emoções nas relações, assim como nas características tendencialmente associadas aos papéis sexuais feminino e masculino.

\section{Dimensões atemporais}

Ao contrário das categorias precedentes (Namoro e Casamento), cujo objetivo era analisá-las sob o ponto de vista temporal, a presente categoria é concernente aos significados de amor e à sua importância, independentemente do fator temporal.

Foi saliente a centralidade e imprescindibilidade do amor em todas as histórias ("É de todo importante na vida a dois, pois só assim é que poderia funcionar" - c5_m), também reconhecidas na literatura científica que o responsabiliza pelo estabelecimento, desenvolvimento e, na ausência, pelo término das relações (Acevedo \& Aron, 2009; Carminatti, 2009; Ribeiro, 2002). Não obstante as dificuldades na sua definição, não havendo uma universal e intemporal mas antes tantas quanto amantes, pôde identificar-se a presença dos três componentes mais comummente considerados paixão, intimidade e compromisso -, com especial relevo para a intimidade, possível sinal de cumprir o casamento funções de proteção. À semelhança de um estudo de Narciso (1994/1995) acerca das significações de amor, privilegiaram o bem-estar e a felicidade do outro ("É preocupar-me mais com o bem-estar dela do que, às vezes, com o nosso" - c3_m), o conforto com a proximidade e o bem-estar quando com o outro ("o amor é aquela vontade de querer partilhar, de querer estar, de me sentir bem ao lado de outra pessoa" c5_m), a aceitação incondicional que permite "gostar apesar de" ("o amor só surge quando se conhece os defeitos da 
outra pessoa." - c1_m), a compreensão mútua ("sentir que a tenho ali e que me compreende e que está comigo" - c5_m), e a amizade.

Ainda assim, amor também significa superação das dificuldades com vista à continuidade ("Vale a pena... adaptar as coisas de forma a continuares a ter essa pessoa" - c1_f), desejo de envelhecer junto do cônjuge ("quereres envelhecer com a pessoa." - c2 f) e investimento permanente ("é preciso... alimentar o amor" - c2 f), o que traduz o compromisso, também expresso na convicção com que os cônjuges declaram a não consideração do término da relação depois de casados.

Apenas um dos cônjuges entrevistados considerou que "o amor continua a significar desejo" (c2 f), atributo característico do componente paixão, e mesmo esse acrescenta que "obviamente que a paixão acaba, ...biologicamente nós não podemos estar sempre num estado de paixão, .... paixão tem de dar lugar a algo mais sustentado", o que a juntar a outras significações ("há a fase de paixão que ...se vai esbatendo... e o amor acho que foi aquilo que foi imperando" -c4_f) permite um entendimento temporal dos componentes do amor, iniciando-se as relações pela fervorosa paixão e continuando-se pela intimidade e compromisso. A concepção de alterações ao nível dos componentes ao longo do tempo ilustra o dinamismo que lhes está inerente, permitindo o desenvolvimento da relação.

Porém, as parcas referências acerca da paixão não significam que esta desaparece por completo com o avançar do relógio relacional, mas podem estar relacionadas com a significativa mediatização e proliferação da sua efemeridade. Uma exploração mais aprofundada poderia ter elucidado melhor a mutabilidade nos componentes do amor. Não obstante a impossibilidade biológica de uma permanência continuada num estado puro e absoluto de paixão, um casal pode reapaixonar-se sucessivamente e experimentar momentos apaixonados. Acevedo e Aron (2009), por exemplo, concluíram que o amor romântico com envolvimento, intensidade e interesse sexual pode manter-se em relações de longa duração, ainda que sem o elemento da obsessão característico das fases iniciais. Esse reconhecimento de que o casamento não tem que ser uma sentença de morte do romance e da paixão pode, segundo eles, ser o mote inspirador que alguns casais precisam para se desafiarem a mudar e a melhorar a qualidade relacional.

\section{Considerações Finais}

Como produto do presente trabalho obtiveram-se várias conclusões, desde logo que nos casais entrevistados os significados associados ao casamento bem como as expectativas para este, para si e para o cônjuge são dimensões sobre as quais não é desenvolvida uma reflexão e discussão intencionalizada, mas que, ainda assim, a harmonia e a felicidade na vida a dois não eram dadas como adquiridas. Os participantes exibiam uma consciência de que uma relação satisfatória pressupõe esforço, resolução de problemas e superação de desafios, fundamental para que a satisfação se efetive e o casal supere momentos de maior tensão (Wright et al., 2007).
Em relação aos significados, o casamento, na fase de namoro, era sinônimo de um projeto que, mais tarde ou mais cedo, teria lugar e que representava uma afirmação do parceiro e da relação. A importância que lhe é atribuída oscila entre dois pólos sendo claramente mais relevante e valorizado por alguns, nomeadamente os que the associam o valor sacramental do matrimónio, do que por outros que destacam a sua dimensão contratual. Casamento era também significado de dificuldade, havendo ainda um participante que o conotava negativamente. Depois de consumado, para a grande parte não se registram alterações nos seus significados, mas houve quem se apercebesse que ele implica dificuldades e que não é uma linear continuidade do namoro e houve ainda quem o resignificasse no sentido positivo.

No que respeita às expectativas, concluiu-se que o casamento, na fase de namoro, era expectado enquanto partilha, fonte de apoio e refúgio contra o mundo exterior, construção de um projeto de vida comum, mais tempo e intimidade e ainda enquanto construção de uma família onde os filhos iriam surgir. Em última instância, a expectativa era de felicidade. Percebeu-se que quer relativamente ao casamento, quer ao cônjuge quer a si próprio, as expectativas, grosso modo, veem-se correspondidas ou superadas.

Relativamente aos conflitos, verificou-se nalguns casais um aumento de conflitos nos primeiros tempos de casamento, ainda que depois, modo geral, todos apontem uma diminuição na frequência comparativamente com o namoro. Concluiuse que há diferenças de género na sua emergência, sendo as mulheres quem mais frequentemente o despoleta. Ao nível das suas fontes, na fase de namoro sobressaíram as características pessoais, o grupo de pares, as diferenças de necessidades e tempos na relação, as experiências relacionais anteriores e as famílias de origem. Na fase de casamento, mantiveram-se os dois primeiros e emergiram a vida profissional e sexual. Quanto às estratégias de resolução - afastamento, tempo, comunicação (padrão exigência-retirada), cedência, oração, humor-, há a manutenção de grande parte delas, destacandose a inexistência do afastamento natural e implícito na condição de namoro, favorável à resolução de conflitos pela oportunidade de relativização e resignificação que encerra, e a acentuação do padrão exigência-retirada.

Portanto, relativamente ao objetivo que visava compreender de que forma namoro e casamento se assumiam realidades (des)contínuas pode perceber-se que este é um caminho tanto marcado por continuidades como descontinuidades, havendo uma simbiose de manutenção e transformação de significações, expectativas e conflitos.

Ainda que encontrando pontos de convergência entre as histórias perscrutadas, ficou saliente a idiossincrasia do percurso afetivo que medeia o namoro e o casamento, o que reforça a necessidade de em psicoterapia, ainda que sabendo existir padrões que norteiam a leitura clínica, atender à especificidade de cada casal e ao seu particular modo de construir, pois cada história tem os seus personagens e narradores. Pese embora as diferenças, foi notória a importância da relação de intimidade para todos os participantes, dando primazia ao "nós" sobre o "eu" (" $A$ minha vida, tudo o que eu faço, tudo o que eu decido no dia a dia é em função, passa pela relação que tenho com [ela]" c1_m), evidenciando uma identidade conjugal construída que 
se fortalece na cedência das individualidades sem que tal gere ansiedade ou as anule (Carminatti, 2009) - " [Ele] é o meu pilar, quer dizer, eu sou o meu pilar!, obviamente, mas ele éo outro pilar." (c2_f). E é no seio dessa interdependência que se situam, sendo por meio dela que se transformam significados e se redefinem projetos, nomeadamente o casamento, pois, afinal, há "sempre a outra pessoa na relação" (c2_f).

Na medida em que se entendeu a transição para a vivência a dois, através da coabitação, enquanto súmula de desafios que implica uma fase de ajustamento (ao "outro", ao "eu com o outro" e ao "nós"), é de considerar a concepção de projetos que reconheçam as relações enquanto objeto de educação. É importante que estes pensem o crescimento do casal e da relação através de uma ação promotora e preventiva em detrimento de uma lógica de remediação, não perpetuando a tendência generalizada de só recorrer à ajuda exterior em momentos de crise e quando o problema já está instalado. É urgente que tanto profissionais de saúde como educadores assumam um papel mais pró-ativo na educação de adolescentes e jovens adultos para a afetividade, inerentemente para a coabitação e para o casamento, dando margem a uma coconstrução de necessidades e intervenção (Morris \& Carter, 1999). Ainda que não seja resposta para todos os desafios do casamento, a educação pré-matrimonial é uma modalidade de intervenção psicológica com potencial preventivo e promotor já bem documentado, devendo ser encarada enquanto recurso em tempos de aceleradas metamorfoses como os de hoje. Tanto nesta como na intervenção clínica é necessário promover a reflexão acerca dos significados e expectativas conjugais, no sentido de as tornar realistas e consistentes entre ambos os protagonistas da relação antes do casamento e assim prevenir a desilusão decorrente de serem defraudadas e, por sua vez, a possível insatisfação conjugal subsequente (Risch, et al., 2003; Torppa, 2009).

Dada a natureza exploratória do presente trabalho e a pouca literatura que olhe simultaneamente para o namoro e o casamento, espera-se que ele tenha constituído uma mais valia e funcione como uma oportunidade de reflexão acerca da (des)continuidade desse trajeto relacional e como um incentivo à continuidade de investigação na área.

\section{Referências}

Aboim, S. (2005). A Formação do Casal: Formas de Entrada e Percursos Conjugais. In K, Wall. (Eds.), Famílias em Portugal Percursos, Interaçções, Relações Sociais (pp. 85-116). Lisboa: Imprensa de Ciências Sociais.

Aboim, S. (2006). Conjugalidades em Mudança. Percursos e Dinâmicas da Vida a Dois. Lisboa: Imprensa de Ciências Sociais.

Acevedo, B. P., \& Aron, A. (2009). Does a long-term relationship kill romantic love? Review of General Psychology, 13(1), 5965. doi: $10.1037 / \mathrm{a} 0014226$

Amaro, F. (2004). A família portuguesa. Tendências actuais. Cidade Solidária. Retrieved from http://ww3.scml.pt/media/revista/ rev_14/Familia_portug.pdf

Bardin, L. (2009). Análise de conteúdo. Lisboa: Edições 70.
Bhatti, R. S. (1993, Junho). Changes in the institution of marriage and family structures: Problems and solutions. Paper presented at the International Conference on Respect for Life: The Priority of the Nineties. St. John's Medical College and Hospital, Bangalore, Karnataka.

Baucom, D. H., \& Epstein, N. (1991). Will the real cognitivebehavioral marital therapy please stand up? Journal of Family Psychology, 4(4), 394-401.

Baucom, D. H., Epstein, N., Daiuto, A. D., Carels, R. A., Rankin, L. A., \& Burnett, C. K. (1996). Cognitions in marriage: The relationship between standards and attributions. Journal of Family Psychology, 10(2), 209-222.

Behrens, B. C., \& Sanders, M. R. (1994) Prevention of marital distress: Current issues in programming and research. Behaviour Change, 11(2), 82-93.

Bonds-Raacke, J. M., Bearden, E. S., Carriere, N. J., Anderson, E. M., \& Nicks, S. D. (2001). Engaging distortions: Are we idealizing marriage? The Journal of Psychology, 135(2), 179-184.

Carminatti, D. (2009). Casamento: A construção de uma nova família. Retrieved from http://www.daniellecarminatti.psc.br/ Artigos/Casamento_Construcao_nova_fam $\% \mathrm{C} 3 \%$ ADlia.pdf

Costa, M. E. (2005). À procura da intimidade. Porto: Edições ASA.

Driver, J. L., \& Gottman, J. M. (2004). Daily marital interactions and positive affect during marital conflict among newlywed couples. Family Process, 43(3), 301-314.

Duarte, C. (2011). Conflito e violência nas relações conjugais: uma perspectiva sistémica. In P.M. Matos, C. Duarte, \& M. E. Costa, (Eds.), Famílias: Questões de Desenvolvimento e Intervenção (pp. 103-123). Porto: LivPsic.

Esere, M. O. (2003). Resolving conflicts in marriages: A counsellor's viewpoint. Journal of Education, 22(1), 26-41.

Faubert, K. M. (2008). "This isn't a fairy taile": An exploration of marital expectations and coping among married women. (Unpublished master's thesis). Miami University.

Faulkner, R. A., Davey, M., \& Davey, A. (2005). Gender-related predictors of change in marital satisfaction and marital conflict. The American Journal of Family Therapy, 33, 61-83. doi: 10.1080/01926180590889211

Fincham, F. D. (2003). Marital conflict: correlates, structure, and context. Psychological Science, 12(1), 23-27.

Fincham, F. D., Beach, S. R. H., \& Davila, J. (2004). Forgiveness and conflict resolution in marriage. Journal of Family Psychology, 18(1), 72-81.

Fletcher, G. J. O., \& Simpson, J. A. (2000). Ideal standards in close relationships: Their structure and functions. Current Directions in Psychological Science, 9(3), 102-105. doi: 10.1111/14678721.00070

Fletcher, G. J. O. (2002). The new science of intimate relationships. USA: Blackwell Publishers.

Flouri, E., \& Buchanan, A. (2001). What predicts traditional attitudes to marriage? Children \& Society, 15, 263-271.

Gottman, J. M. (1991). Predicting the longitudinal course of marriages. Journal of Marital and Family Therapy, 17(1), 3-7.

Gottman, J. M., \& Notarius, C. I. (2002). Marital research in the 20 th century and a research agenda for the 21 th century. Family Process, 41(2), 159-198.

Greeff, A. P., \& Bruyne, T. (2000). Conflict management style and marital satisfaction. Journal of Sex \& Marital Therapy, 26, 321-334. doi: 10.1080/009262300438724 
Hall, S. S. (2006). Marital meaning: Exploring young adult's belief systems about marriage. Journal of Family Issues, 27(10), 1437-1458. doi: 10.1177/0192513X06290036

Holmes, B. M., \& Johnson, K. R. (2009). Where fantasy meets reality: Media exposure, relationships beliefs and standards, and the moderating effect of a current relationship. In E.P. Lamont (Ed.), Social psychology: New research (pp. 117-134) Nova Iorque: Nova Science Publishers.

Instituto Nacional de Estatística (2010). Anuário Estatístico de Portugal 2008 - Edição 2009. Lisboa: Instituto Nacional de Estatística.

Jares, X. R. (2002). Educação e conflito: Guia de educação para a convivência. Porto: Edições ASA.

Juvva, S., \& Bhatti, R. S. (2006). Epigenetic model of marital expectations. Contemporary Family Therapy, 28(1), 61-72. doi: 10.1007/s10591-006-9695-2

Kefalas, M., Furstenberg. F., \& Napolitano, L. (2005). Marriage is more than being together: The meaning of marriage among young adults in the United States. The Network on Transitions to Adulthood. Retrieved from http://www.transad.pop.upenn. edu/downloads/kefalasmarriagenorms.pdf

Leite, S. (2003). A união de facto em Portugal. Revista de Estudos Demográficos, 33, 97-140.

Lindahl, K. M., Malik, N. M., \& Bradbury, T. N. (1997). The developmental course of couples' relationships. In W. K. Halford, \& H. J. Markman (Eds.), Clinical handbook of marriage and couples intervention (pp. 203-223). Chichester: John Wiley \& Sons Ltd.

Markman, H. J., Floyd, F. J., Stanley, S., \& Jamieson, K. (1984). A cognitive/behavioral program for the prevention of marital and family distress: Issues in program evaluation and delivery. In K. Hahlweg \& N. Jacobson (Eds.), Marital interaction: Analysis and modification (pp. 396-428). New York: Guilford Press.

Markman, H. J., Rhoades, G. K., Stanley, S. M., Ragan, E. P., \& Whitton, S. W. (2010). The premarital communication roots of marital distress and divorce: The first five years of marriage. Journal of Family Psychology, 24(3), 289-298. doi: 10.1037/ a0019481

Martin, P. D., Specter, G., Martin, D., \& Martin, M. (2003). Expressed attitudes of adolescents toward marriage and family life. Adolescence, 38(150), 359-367.

McNulty, J. K., \& Karney, B. R. (2004). Positive expectations in the early years of marriage: Should couples expect the best or brace for the worst? Journal of Personality and Social Psychology, 86(5), 729-743. doi: 10.1037/0022-3514.86.5.729

Morris, M. L., \& Carter, S. A. (1999). Transition marriage: A literature review. Journal of Family and Consumer Sciences Education, 17(1), 1-24.

Myers, M. F. (1998). How's your marriage? A book for men and women. U.S.A.: American Psychiatric Press.

Narciso, I. (1994/95). Metamorfoses do amor e da satisfação conjugal. Cadernos de Consulta Psicológica, 10/11, 129-139.

Oltramari, L. C. (2009). Amor e conjugalidade na contemporaneidade: Uma revisão de literatura. Psicologia em Estudo, 14(4), 669677.

Ribeiro, T. (2002). Da diversidade do feminino e do masculino à singularidade do casal. (Unpublished doctoral dissertation). Universidade de Lisboa.
Risch, G. S., Riley, L. A., \& Lawler, M. G. (2003). Problematic issues in the early years of marriage: Content for premarital education. Journal of Psychology and Theology, 31(3), 253269.

Rosa, C. P. (2009). A identidade dialógica de um prisma empírico: Um estudo sobre a conjugalidade. (Unpublished doctoral dissertation). Universidade do Minho, Braga.

Senécal, C., Vallerand, R. J., \& Guay, F. (2001). Antecedents and outcomes of work-family conflict: Toward a motivational model. Society for Personality and Social Psychology, 27(2), 176-186.

Shulman, S., Rosenheim, E., \& Knafo, D. (1999). The interface of adolescent and parent marital expectations. The American Journal of Family Therapy, 27, 213-222.

Sternberg, R. J. (1986). A triangular theory of love. Psychological Review, 93(2), 119-135.

Torppa, C. B. (2009). Preparing adolescents and young adults for marriage: Developing realistic expectations for family communication. Fact sheet. Family and Consumer Sciences. Retrieved from http://ohioline.osu.edu/flm00/pdf/fs04.pdf

Verhofstadt, L. L., Buysse, A., Clercq, A., \& Goodwin, R. (2005). Emotional arousal and negative affect in marital conflict: The influence of gender, conflict structure, and demand-withdrawal. European Journal of Social Psychology, 35, 449-467. doi: 10.1002/ejsp.262

Wright, D. W., Simmons, L. A., \& Campbell, K. (2007). Does a marriage ideal exist? Using Q-sort methodology to compare young adults and professional educators' views on healthy marriages. Contemporary Family Therapy, 29(4), 22. 